\title{
Efectos de la
}

Importancia del

Usuario en la Web $\mathbf{2 . 0}$

Iván Adell Ortega.

Antonio García Solana.

Roberto Huertas Muyo.

Róger Moragas Quesada.

Jordi Ruiz Guisado. 


\section{Índice}

Introducción

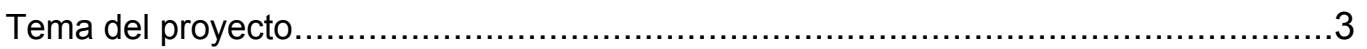

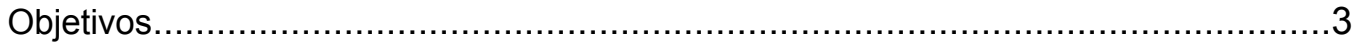

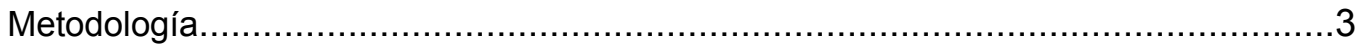

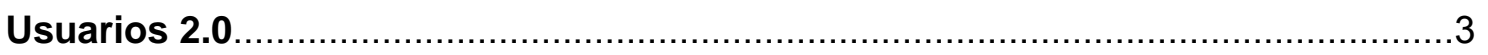

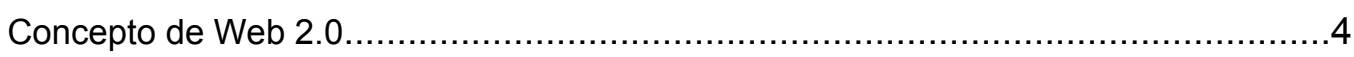

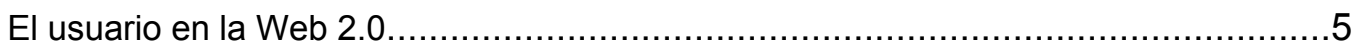

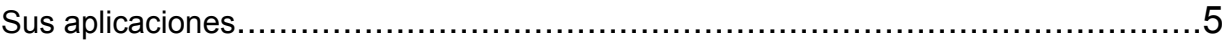

La Web 2.0 aplicada a la educación online .................................................

Efectos de la importancia de los usarios en la Web 2.0 ....................................

Aumento de las redes sociales a través de Internet.............................................

Contenidos. Aprovechando la inteligencia colectiva..............................................

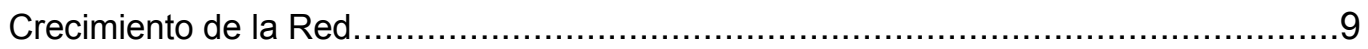

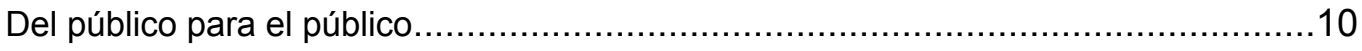

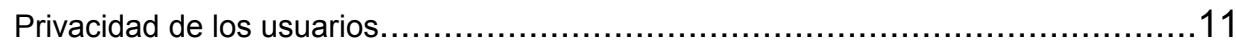

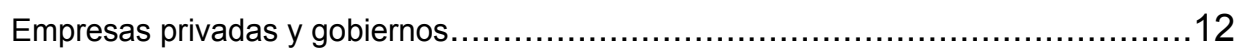

Blogs, cambios y cómo y quién dirige la información a las masas.........................12

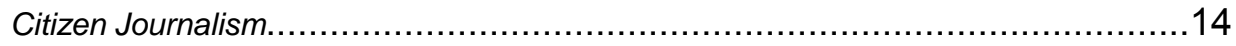

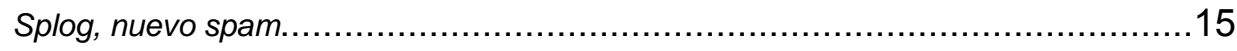

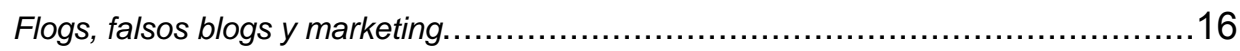

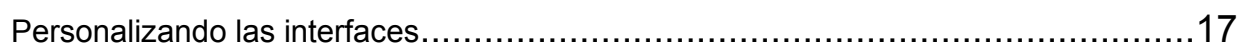

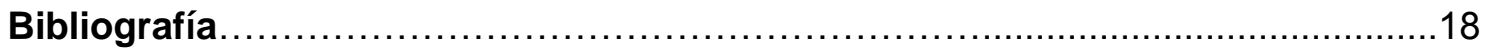

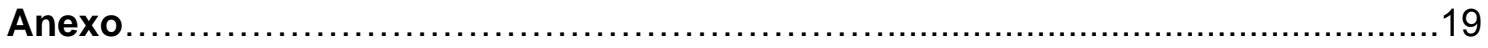




\section{Introducción}

En esta sección se introducen los objetivos del proyecto y se detalla cómo se ha llevado a cabo el mismo.

\section{Tema del proyecto}

El tema escogido para la realización del proyecto final es "Efectos de la Importancia del Usuario en la Web 2.0."

El usuario que en la Web 1.0 era un mero espectador, pasa en la Web 2.0 a ser el protagonista. Estudiaremos los cambios experimentados por este cambio de rol y las consecuencias que puede conllevar.

\section{Objetivos}

El principal objetivo del proyecto es entender el papel que juega el usuario en la Web 2.0. Este rol es clave para entender el presente y el futuro de Internet. También se estudiará como afecta la inseguridad existente en estas tecnologías y si es tan importante como a priori parece.

\section{Metodología}

Para la redacción del proyecto se ha utilizado la siguiente metodología, basada en tres puntos principales:

1. Participación en el debate virtual, concretando el tema a desarrollar en este proyecto, sintetizando las opiniones generadas en éste.

2. Realización de búsquedas de información relacionadas con el tema escogido, especialmente a través de Internet. Planificación de la ejecución del proyecto.

3. Tratamiento de la información y de los datos recopilados, haciendo un análisis de éstas para realizar la redacción del proyecto.

\section{Usuarios 2.0}

En este punto definiremos qué es la Web 2.0, los orígenes del término, así como las aplicaciones que ofrece al usuario. También se dará una pequeña introducción a la importancia que el usuario tiene en la Web 2.0, punto central del proyecto que se tratará en profundidad en el punto 3. Para finalizar este punto trataremos la aportación de la Web 2.0 en la educación en línea. 


\section{Concepto de Web 2.0}

Podemos definir la Web 2.0 como una segunda generación de webs basadas en comunidades de usuarios y una gama especial de servicios, como las redes sociales, los blogs, los wikis o las folcsonomías, que fomentan la colaboración y el intercambio ágil de información entre los usuarios.

Los orígenes del término Web 2.0 se remontan al 2004 en una sesión de brainstorning realizada entre O'Reailly y Medialive International. En esta se observó que lejos de estrellarse, la Web era más importante que nunca, con apasionantes nuevas aplicaciones y con sitios web apareciendo con sorprendente regularidad. Decidieron realizar la conferencia de la Web 2.0. En esta primera reunión formulan su interpretación de la Web 2.0 con un ejemplo:

\begin{tabular}{|c|}
\hline Web 1.0 \\
\hline Doble Click \\
\hline Ofoto \\
\hline Akamai \\
\hline Mp3.com \\
\hline Británica online \\
\hline Personal Websites \\
\hline Evite \\
\hline Domain name speculation \\
\hline Page views \\
\hline Screen scraping \\
\hline Publishing \\
\hline Content management systems \\
\hline Directories (taxonomy) \\
\hline Stickiness \\
\hline
\end{tabular}

\begin{tabular}{|c|}
\hline Web 2.0 \\
\hline Google AdSense \\
\hline Flickr \\
\hline BitTorrent \\
\hline Napster \\
\hline Wikipedia \\
\hline Blogging \\
\hline Upcoming.org and EVDB \\
\hline Search engine optimization \\
\hline Cost per clic \\
\hline Web services \\
\hline Participation \\
\hline Wikis \\
\hline Tagging ('folksonomy') \\
\hline Syndication \\
\hline
\end{tabular}

Figura 1: Aplicaciones de la Web 2.0.

La Web 2.0 utiliza una tecnología compleja y que va evolucionando, utiliza técnicas como: CSS, técnicas de aplicaciones ricas no intrusivas (como Ajax), Java Web Star, XUL, sindicación de datos en RSS/ATOM, URLs sencillas y con significado, soporte para escrbir un blog, JCC y APIs REST o XML, algunos aspectos de redes sociales. En general podemos decir que una web pertenece a la Web 2.0 si tiene las siguientes características:

- El sitio no debe actuar como un "jardín cerrado": la información debe poderse introducir y extraer fácilmente.

- Los usuarios deberían poder controlar su propia información. 
- Basada exclusivamente en la Web: los sitios Web 2.0 con más éxito pueden ser utilizados enteramente desde un navegador.

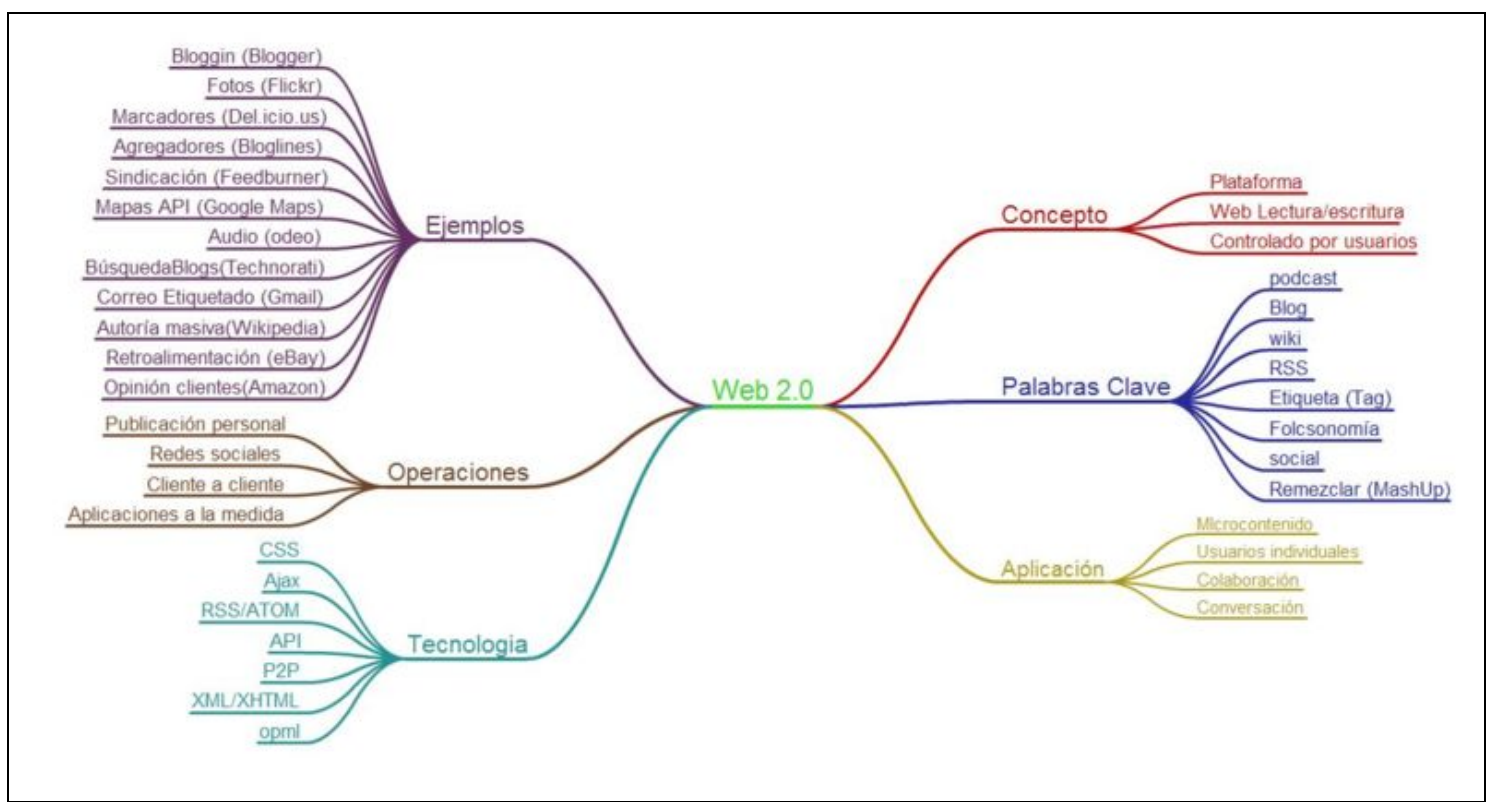

Figura 2: Mapa mental de la Web 2.0 (Fuente: Wikipedia)

\section{El usuario en la Web 2.0}

El usuario es la verdadera revolución en la Web 2.0. La Web 1.0 se trataba de un grupo de páginas casi estáticas donde la gente podía observar contenidos predeterminados. Con la aparición de sistemas basados en web (correos electrónicos, compras en línea, foros de discusión, entre otros), la Web se convirtió en una plataforma donde la gente intercambia ideas, mensajes o productos de acuerdo con sus necesidades.

\section{Sus aplicaciones}

Las aplicaciones que la Web 2.0 ofrece al usuario son infinitas, desde weblogs (los ya conocidos diarios personales online, con comentarios y citas cruzadas a otros weblogs); sitios como Flickr o Myspace donde se comparten juegos, vídeos, fotografías; se difunden noticias mediante podcasting (archivos de sonido que se descargan y se pueden escuchar y reproducir en cualquier momento); se coeditan de forma participativa enciclopedias en línea, como Wikipedia; se consultan o cuelgan anuncios clasificados en Craigslist o Loquo; se añaden textos o tags (la llamada folksonomia); hasta las fotografías, música, etc., que se cuelgan en la Red, para que otros las puedan buscar en sitios web como Del.icio.us, etc. La lista puede no acabar nunca, ya que cada día nacen nuevas aplicaciones. Adjuntamos una web en la que aparecen mil aplicaciones Web 2.0 divididas según su utilidad: 


\section{$\rightarrow$ http://k40s.wordpress.com/2006/12/19/mas-de-1000-aplicaciones-web20/}

Esta enorme actividad está cambiando el mundo de las telecomunicaciones, de los medios de comunicación, del marketing, del software, del entretenimiento, etc. Claramente ha habido una transición de las aplicaciones tradicionales hacia aplicaciones que funcionan a través de la Web enfocadas en el usuario final. Se trata de aplicaciones que generen colaboración y de servicios que reemplacen las aplicaciones de escritorio.

\section{La Web 2.0 aplicada a la educación online}

La educación en línea es uno de los sectores donde ha existido un desarrollo limitado debido a ciertos prejuicios sostenidos por educadores tradicionales y estudiantes. Sin embargo, la Web 2.0 nos da la oportunidad de desarrollar nuevos sistemas y métodos para la educación en línea, aprovechando las capacidades de interacción desarrolladas en los últimos años.

La explosión de sitios sociales, donde la gente comparte información y conocimientos, promueve una nueva tendencia hacia la creación de una inteligencia común y colectiva creada por y para los usuarios. Esta desmitificación del profesor como un gurú indiscutible promueve el aprendizaje colaborativo tan deseado por diversas corrientes de la pedagogía virtual, y debe ser aprovechada y tomada en cuenta por los nuevos modelos y métodos de educación virtual.

Independientemente de la edad, las personas buscan en la educación no conocimientos inútiles o descontextualizados, sino ideas relevantes para la vida diaria.

Es en ese sentido que muchas veces los grandes proveedores de conocimiento (antes las enciclopedias, diccionarios o expertos) no incluyen información verdaderamente relevante, y es ahí donde la recolección de conocimientos colectivos entra en juego. Integrar a los alumnos en momentos clave del proceso educativo y no sólo verlos como receptores pasivos de información con breves destellos de participación es el principal reto de la educación virtual.

\section{Efectos de la importancia de los usuarios en la Web 2.0}

Los propios usuarios son los únicos que con sus aportaciones son el pilar fundamental para el domino de la era Web 2.0. Ellos mismos son los que tienen que crear una estrategia de confianza para conseguir una mejora dentro de este campo tan amplio. El mal uso de esta es el principal obstáculo, la cual esta creando un distanciamiento entre las relaciones humanas causadas por los propios usuarios. Sin hacer mal uso, el futuro de Web 2.0 sin duda, está en continua expansión con buenas propuestas de futuro. 


\section{Aumento de las redes sociales a través de Internet}

Las redes sociales en Internet se han ganado un puesto convirtiéndose en supuestos negocios para empresas y destacadamente en lugares de encuentros humanos.

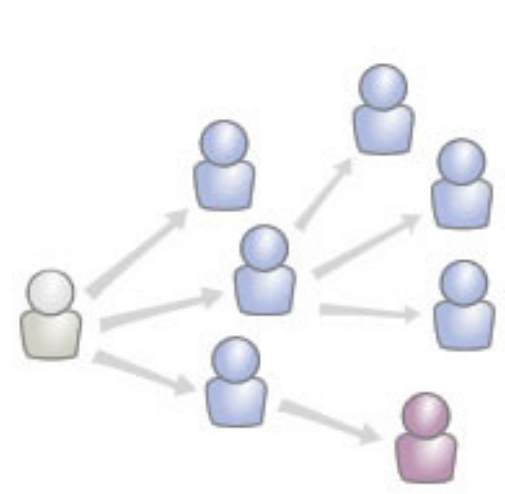

Entre 2001 y 2002 surgen los primeros sitios que fomentan redes de amigos. De cara el 2003, ya un poco más personalizado, aparecen sitios como el destacado myspace.com, friendsler.com o tribe.net.

Realmente el auge de las redes sociales empieza cuando el soporte técnico está montado.

El grupo que inicia invita a amigos a formar parte de la red social, lo que provoca una reacción en cadena y su repentino y abismal crecimiento.

En las redes sociales tenemos la posibilidad de interactuar con otras personas aunque no las conozcamos. El sistema es abierto y se va construyendo obviamente con lo que cada suscrito a la red aporta. Cada nuevo miembro que ingresa transforma al grupo en otro nuevo. La red no es lo mismo si uno de sus miembros deja de ser parte.

Las redes sociales proporcionan herramientas en Internet, destacamos:

- Actualización automática de la libreta de direcciones

- Perfiles visibles

- Capacidad de crear nuevos enlaces mediante servicios de presentación y otras maneras de conexión social en línea

Las redes sociales van relacionadas con una parte social, es decir, redes relacionadas a la cultura general, compartir música y fotos, búsqueda de parejas o amigos, fomentar relaciones profesionales, hacer negocios, entablar simplemente una conversación o intereses comunes.

Destacamos algunas de las siguientes redes en cuanto a habla hispana: 


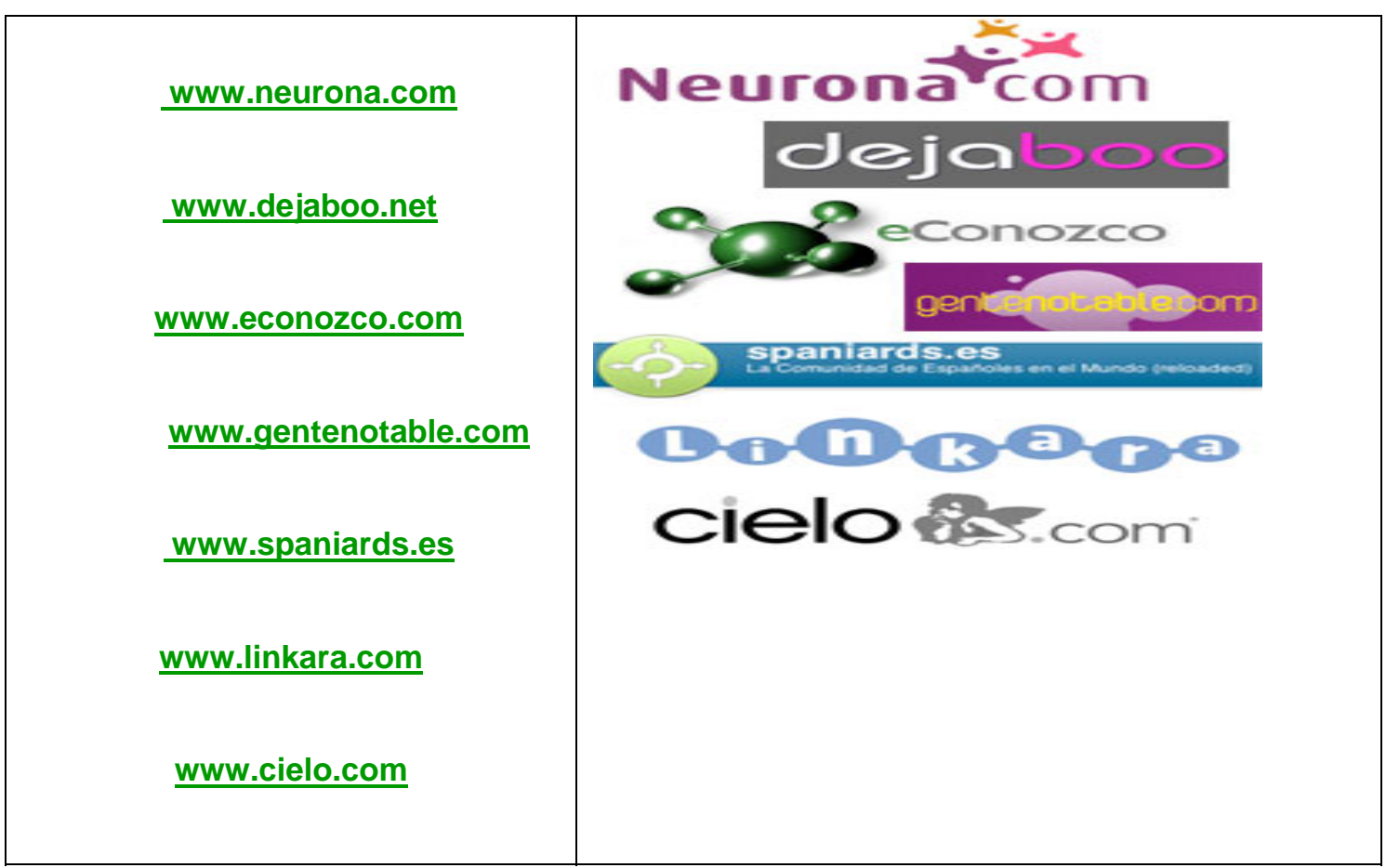

Figura 3: Redes de habla hispana (Fuente: Google).

\section{Contenidos. Aprovechando la inteligencia colectiva}

Los usuarios y la interacción que hay entre ellos son la principal fortaleza de estas aplicaciones.

A medida que los usuarios suben contenido nuevo y sitios webs, se enlazan con la estructura de la Web gracias a otros usuarios que descubren el contenido y se enlazan a él.

Existen pequeñas aplicaciones en que los propios usuarios participan en ellas para conseguir ciertos resultados. Es decir, tratan de unificar esfuerzos y conocimientos recogidos desde todas partes del mundo para conseguir un fin.

Los usuarios registrándose y cumplimentado un pequeño formulario personal, si hace falta, puede aportar toda la información que desee y ésta estará disponible para que millones de personas la puedan ver y/o utilizar o simplemente calificar.

Un ejemplo es Wikipedia, una enciclopedia creada para que centenares de personas participen en su desarrollo. Creada en 2001 por la Fundación Wikimedia, es uno de los 25 sitios más visitados del mundo y cuenta con más de un millón y medio de artículos en inglés y aproximadamente 178.000 en español.

Su utilización es tan simple que el propio usuario puede agregar información y ésta puede ser corregida por cualquier otro.

Actualmente y a pesar de sus críticas, es una de las fuentes de conocimiento más consultadas en Internet. 
Hay una gran cantidad de aplicaciones que ofrecen gran variedad de servicios que se pueden utilizar desde diferentes navegadores, como Explorer, Firefox, Safari o Flock.

Existen aplicaciones gratuitas en formato beta, una gran mayoría, ya que son aplicaciones que los mismos usuarios las van retroalimentando constantemente.

Destacamos 10 las cuales pueden ser de gran utilidad:

- www.gmail.com

- www.youtube.com

- www.flickr.com

- www27.meebo.com/index-es.html

- www.basecamphq.com
- www.openomy.com

- www.zohowriter.com

- www.netvibes.com

- www.synchroedit.com

- www.pytagor.com

Las contribuciones que hacen los usuarios son la clave para el dominio del mercado en la era Web 2.0 y para su continua expansión de cara al futuro.

\section{Crecimiento de la Red}

La interacción entre los usuarios ha derivado en un acelerado crecimiento del Internet, la cual aumenta cada dos semanas la oferta de información en un $1 \%$.

Gracias a las estadísticas realizadas por Morgan Stanley(1) sobre el estado de Internet a nivel mundial, podemos observar qué páginas son las más visitadas y las que más crecimiento han experimentado en el último año.

Entre las páginas más visitadas encontramos liderando el ranking a Microsoft, Yahoo! y Google.

Podemos observar cómo dos de las tres primeras webs apuestan claramente por la Web 2.0. Pero observando el crecimiento, el dato más significativo resulta ser ver qué dos páginas han sido las que más crecimiento han experimentado: Wikipedia y YouTube. Siendo ésta última, la web en Internet con un mayor crecimiento en el último año y superando de largo a webs que lideran el ranking, por lo que es de esperar que el año que viene se sitúe entre las cinco primeras del mundo en cuanto a visitas se refiere. 


\section{User-Generated Content (UGC) - Wikipedia + MySpace + YouTube Have Moved to Top of Internet User Pack}

\begin{tabular}{clcc} 
& & \multicolumn{2}{c}{ Total Global Unique Visitors (MM) } \\
\cline { 2 - 4 } Rank & Property & $9 / 06$ & Y/Y Growth \\
\hline 1 & Microsoft & 505 & $5 \%$ \\
2 & Yahoo! & 481 & 8 \\
3 & Google & 467 & 11 \\
4 & eBay & 237 & 4 \\
5 & Time Warner & 218 & 20 \\
6 & Wikipedia & 155 & 110 \\
7 & Amazon & 134 & 9 \\
8 & Fox & 118 & 303 \\
9 & Ask & 113 & $(0)$ \\
10 & Adobe & 95 & 5 \\
11 & Apple & 95 & 38 \\
12 & Lycos & 91 & $(3)$ \\
13 & CNET & 84 & $(10)$ \\
14 & YouTube & 81 & 2,662 \\
15 & Viacom & 66 & - \\
& & & Source: comScore Madia Mebrix Glabal Data \\
& & &
\end{tabular}

Morgan Stanley

Figura 4: Usuario de Gestión de Contenidos (Fuente: Morgan Stanley).

También cabe destacar el aumento producido en España, que según noticia aparecida en prensa (2) "lidera en Europa el uso de la Web 2.0". España es el país en el que más blogs se crean.

Todos estos datos no hacen más que reflejar la importancia que está teniendo la Web 2.0, que junto a otros hechos también muy significativos, como el aumento de conexiones de banda ancha y la reducción de los precios de conexión, están provocando una segunda oleada de crecimiento tanto en los contenidos de Internet como de los propios usuarios.

Según el estudio realizado por Morgan Stanley, este crecimiento es del $10-15 \%$ en crecimiento de usuarios y del $20-30 \%$ en el uso de Internet.

\section{Del público para el público}

Si el lema del despotismo ilustrado era "todo para el pueblo pero sin el pueblo", está claro que el de la democracia es "del pueblo, para el pueblo y por el pueblo". Del mismo modo, la Web 2.0 ha tomado el lema democrático y lo ha llevado a su terreno favoreciendo la participación del usuario en su propio beneficio y llevando su implicación hasta puntos insospechados hasta el momento en Internet.

El contenido generado por el usuario o UGC (user-generated content) se expande por toda la Web y amenaza con cambiar ciertos sectores que estaban establecidos hasta 
el momento, tales como el periodismo tradicional y el sector del entretenimiento audiovisual.

Tal es la importancia de esta revolución en la Red que el usuario pasa a ser la pieza central de ella. No obstante, a pesar de esta aparente ebullición de contenido generado por el propio usuario en Internet, recientes estudios (3) demuestran que la teoría de Nielsen del 90-9-1 parece ser cierta.

Dicha teoría afirma que el $\mathbf{9 0} \%$ de usuarios (Nielsen los llama lurkers) no contribuye. El $9 \%$ restante participa ocasionalmente, mientras que es el $1 \%$ el que realmente crea todo el contenido (4).

A pesar de ello, no se puede negar la importancia del contenido generado por el usuario y de la Web 2.0, ya que incluso las grandes empresas del sector informático están en busca de unos apetecibles beneficios económicos. Como ejemplo, hemos visto como Google adquiría YouTube hace aproximadamente un año (5) y muy recientemente FeedBurner (6), ambas compañías insignia de la Web 2.0.

\section{Privacidad de los usuarios}

Posibilidad del abuso de la privacidad de los usuarios de la Web 2.0 por parte de terceros. Los propios usuarios son una parte imprescindible para crear, participar y compartir contenidos, pero pueden surgir algunas desventajas como es perder el control de sus contenidos.

Algunas empresas utilizan esta información (datos personales, profesionales, videos etc.) para transferirla a terceros, eso sí, a cambio se les proporciona una licencia mundial gratuita. El verdadero problema es con qué finalidad emplean esta compañías los datos personales de cada persona.

Un claro ejemplo sería el correo electrónico Gmail de Google, el cual puede rastrear con cierta facilidad los mensajes de cada usuario aprovechándose de sus contenidos. Con este tipo de análisis, Google puede conseguir información de éste y de esta manera, los consumidores reciben anuncios publicitarios relacionados con lo analizado anteriormente en el correo electrónico.

También es cierto decir, que algunos espacios como Youtube, Myspace, Groups Google o foros, archivan con cierta facilidad todos los mensajes, vídeos u opiniones expuestos en la Web.

Por eso, en la mayoría de aplicaciones de la Web 2.0 es conveniente consultar sus condiciones de servicios ("letra pequeña") para evitar posibles confusiones referentes a la privacidad del usuario. 


\section{Empresas privadas y gobiernos}

En este apartado enfocaremos los intereses de estas organizaciones en tres grandes ámbitos:

1. Ofrecer un servicio: Aunque puede ser difícil de entender, existen empresas que se basan en un proyecto personal, y no tienen en cuenta el interés económico. Su finalidad es dar un servicio a la comunidad de usuarios y si existieran beneficios, éstos se destinan al propio servicio o a su gestión. Es el caso de del.icio.us, que es un espacio para compartir y organizar enlaces.

2. Supervivencia: La capacidad social y relacional que existe tras el concepto de Web 2.0 es un importante requisito para que estas organizaciones sobrevivan. Esto significa que las empresas han de estar conectadas y establecer diálogos con los usuarios.

3. Intereses económicos: La mayoría de las empresas privadas de Internet se mueven por intereses económicos. La finalidad de éstas es conseguir un alto nivel de audiencia, es decir, a mayor número de usuarios compartiendo contenidos, mayor utilidad del servicio propuesto y por tanto mayor beneficio. Dentro de las modalidades de audiencia encontramos la publicidad, que se ha convertido en un gran negocio para estas organizaciones. Por ejemplo, Google ingresó 2.690 millones de dólares en el tercer trimestre del 2006 y el $99 \%$ de éstos provienen de la publicidad.

Por otro lado, se produce un control de la información de los usuarios por parte de los gobiernos a través de las empresas privadas. Existe tal cantidad de información en la Red, que algunas empresas como Google o Yahoo se ven obligadas a ceder estos contenidos a gobiernos no democráticos.

Durante el pasado año hubo tensiones entre los buscadores y las autoridades chinas. El gobierno chino presionó a Yahoo, que colaboró en la detención de un periodista disidente, y recibió duras críticas por parte de Estados Unidos, aunque el gobierno estadounidense presionó a los servicios de las Web 2.0 para conseguir información de los usuarios y así hacer frente al terrorismo.

Blogs, cambios y cómo y quién dirige la información a las masas

Los weblogs o blogs son una parte muy importante de la Web 2.0. Se conoce como blogs a sitios webs que presentan una frecuencia de actualización relativamente alta y un formato donde los contenidos se organizan en orden cronológico inverso. Podemos 
encontrar blogs de tipos varios y diversos, desde blogs de contenidos de carácter personal hasta blogs profesionales.

Los weblogs son una de las herramientas fundamentales a través de las cuales se configura la esencia de la Web 2.0, ya que a través de ellos millones de personas pueden expresarse libremente y obtener información al margen del mainstream comunicativo. Este hecho ha dado lugar a toda una cultura blog y a una serie de fenómenos asociados.

El auge de los weblogs ha surgido sobretodo debido a su facilidad de creación con herramientas tipo Blogger o Wordpress. En menos de 10 minutos cualquier persona puede tener un blog y postear vía correo electrónico para su mayor comodidad.

Según un estudio de Technorati (7), se crean más de 120.000 blogs nuevos cada día, lo cual nos puede dar una idea de lo importante del fenómeno.

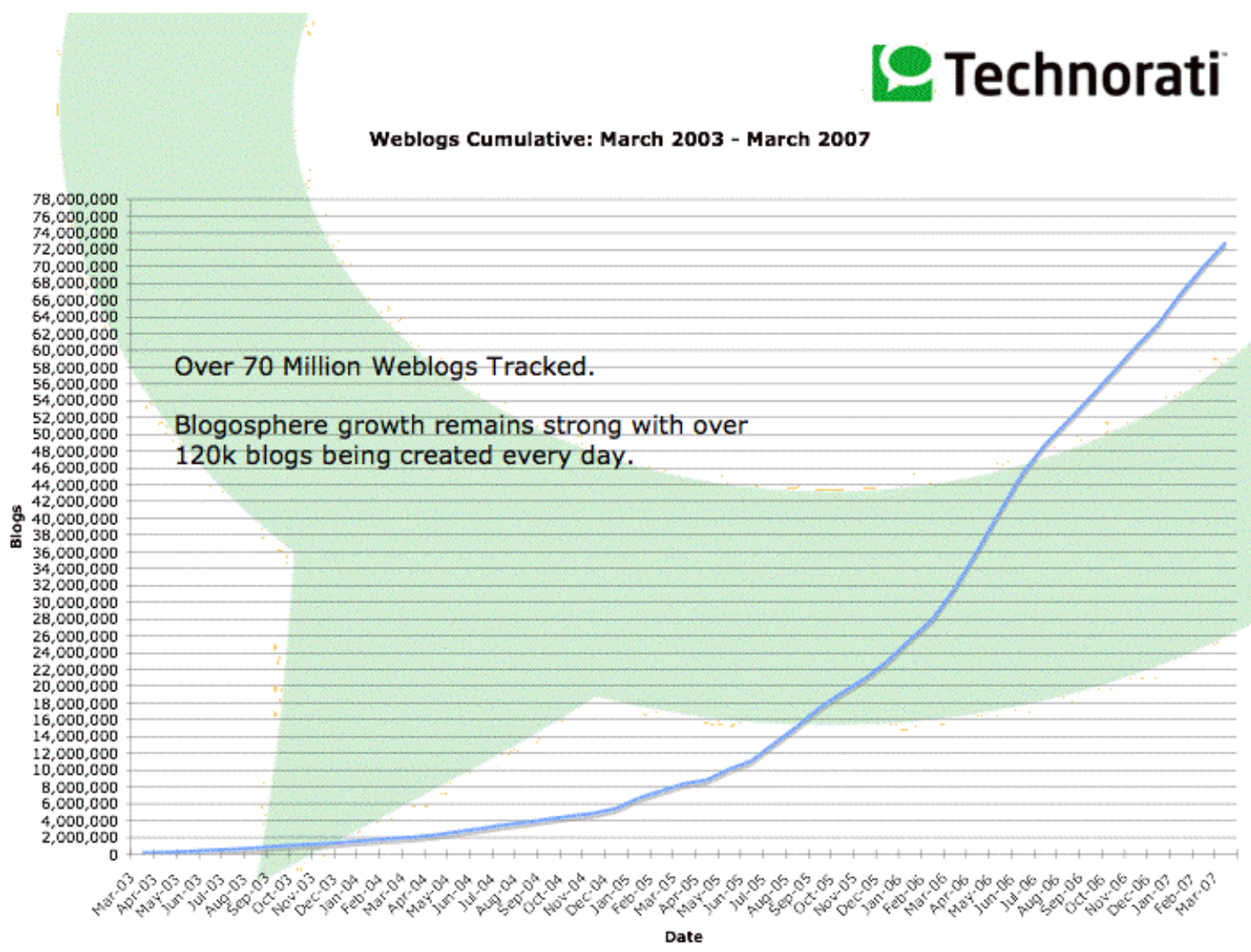

Figura 5: Crecimiento de la blogosfera (Fuente: Technorati).

No sólo eso, los operadores móviles ya están llevando los blogs a los teléfonos móviles aprovechando el tirón que este mercado les brinda. Políticos, actores, escritores, pocos son ya los que se resisten a los encantos de este nuevo fenómeno comunicativo. 
$Y$ es que no debemos olvidar que mucha gente basa sus opiniones en las informaciones que obtiene de los weblogs, que cada vez compiten con los medios establecidos (8).

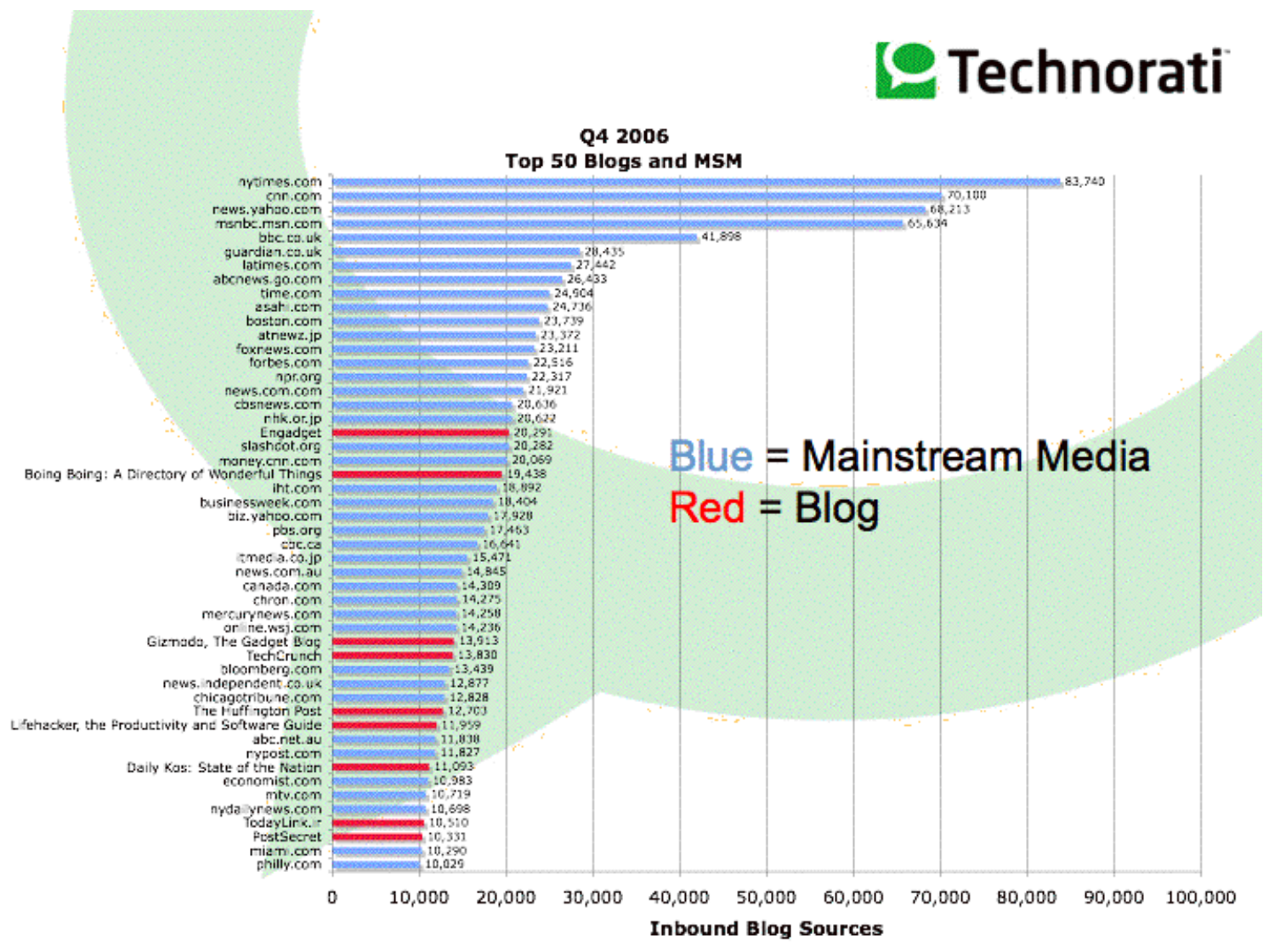

Figura 6: Blogs versus Medios convencionales (Fuente: Technorati).

Otro de los puntos que nos pueden ayudar a entender la importancia de los weblogs en la Web 2.0 es que ciertos buscadores usan los enlaces que aparecen en ellos para poder indexar adecuadamente las noticias de mayor importancia.

En definitiva, los weblogs configuran una parte importantísima, sino la más, de la Web 2.0 .

\section{Citizen Journalism}

El citizen journalism o periodismo ciudadano, también conocido como periodismo participativo o periodismo 3.0, representa el fenómeno mediante el cual personas sin conocimiento profesional del periodismo usan las posibilidades que les brinda la tecnología para crear y difundir sus propias noticias o comentar las de otros dando su visión de los hechos.

Este fenómeno es muy activo en la Web 2.0 y los blogs han ayudado bastante a expandirlo. A través de ellos y la facilidad de publicación de contenidos que ofrecen, 
así como la facilidad de difusión de la información a nivel internacional que también posibilitan, el periodismo ciudadano ha crecido no sólo a nivel cuantitativo.

Existen críticas a este fenómeno que, sin duda, tiene un gran impacto en el status quo mediático. Algunos medios tradicionales acusan al citizen journalism de haber perdido uno de los valores más importantes del periodismo: la búsqueda de la objetividad.

Sin embargo, no se puede obviar que el periodismo ciudadano es un hecho. Así, hemos visto como a través de los blogs nos llegaban historias o sucesos de lugares asolados por la guerra y sometidos a un estricto control del flujo de información por los medios de comunicación de masas tradicionales, o como se destapaba el 'affair Clinton' a través del weblog del periodista Matt Drudge (9).

Asimismo estamos asistiendo al fenómeno de adecuación que están llevando a cabo los medios tradicionales. Actualmente podemos observar como muchas webs de diarios y periódicos incorporan herramientas típicas del blog y permiten a los usuarios dejar comentarios y generar opinión y contenidos.

El gran miedo que estos medios tienen frente al periodismo ciudadano es que les acabe quitando una parte importante de su negocio, ya que ven como poco a poco están perdiendo la hegemonía sobre el control de la información. Ante los grandes monopolios de la información, el periodismo ciudadano se alza como una nueva forma de libertad y expresión.

\section{Splogs, nuevo spam}

La democratización y libertad para publicar cualquier tipo de información puede provocar la aparición de información incorrecta y malintencionada.

Esta información viene acompañada de ofertas comerciales, por lo que normalmente es de tipo publicitario. Es lo que denominamos splog (palabra que proviene de contraer la expresión spam blog del inglés).

Los splogs tienen como principal finalidad promocionar sitios web afiliados, donde pueden mejorar su posición ante los motores de búsqueda tales como Google o Yahoo. A partir del número de enlaces al sitio web desde otros sitios, consiguen lograr altos números en los resultados de búsqueda. 
Suelen emplear el correo electrónico como vía habitual. Ésta consiste en enviar un gran número de mensajes idénticos o casi idénticos a un elevado número de usuarios. El envío de esta información se produce sin el consentimiento del consumidor.

De esta manera al recibir un correo no solicitado, es recomendable borrarlo sin leerlo.

En general, los problemas más comunes de los splogs o spam blogs se dividen en tres vertientes:

1. Se han convertido en una amenaza en los servicios de alojamiento gratuito de blogs. Este tipo de blogs desperdicia espacio en el disco duro del ordenador y el ancho de banda de Internet.

2. Pueden provocar dificultades para los usuarios en la búsqueda de información en los blogs, ya que usan un nombre parecido al de un blog de buena reputación y así confundirlos.

3. Los auténticos autores de los blogs se pueden ver perjudicados, si los buscadores intentan solucionar el problema bloqueando o marcando como sospechosos todos los sitios web bajo un domino de Internet como info o net.

Otras tecnologías en la Web que han sido objeto de correo malintencionado son grupos de noticias usenet, wikis y foros.

\section{Flogs, falsos blogs y marketing}

Gracias a la Web 2.0 se ha podido crear un dialogo directo entre las empresas y los consumidores. Pero algunas empresas se han aprovechado de esta situación para hacerse pasar por consumidores satisfechos del producto.

La gran explosión de información que ha generado la Web 2.0 ha creado un nuevo mundo que explotar para las empresas privadas. Empresas ávidas de encontrar nuevos clientes, que aprovechan cualquier situación para desplegar grandes campañas publicitarias rayando incluso en la ilegalidad.

Los blogs, una de las principales fuentes de información en la nueva Internet, ha sido el campo escogido por las empresas privadas, llegando a crear falsos blogs (flogs) donde se alaban sus productos por supuestos clientes o incluso llegando a pagar dinero a usuarios con blogs muy visitados para mencionar sus últimos productos. 
En Estados Unidos ya han sido multadas varias empresas privadas, empresas de renombre mundial, por realizar estas prácticas ilegales de publicidad.

Los blogs son uno de los nuevos fenómenos creados en Internet, ¿pero toda la información que se está publicando es real?

\section{Personalizando las interfaces}

En este punto analizaremos cómo el usuario crea, modifica y rediseña la apariencia de Internet.

Las nuevas tecnologías utilizadas por Web 2.0 han dado un papel inesperado al propio usuario: históricamente había sido un mero espectador en Internet y ahora el usuario pasa a controlar no sólo el contenido publicado, sino a ejercer el papel de diseñador. Diseños, por norma sencillos, pero que permiten personalizar interfaces.

Gracias a páginas de inicio personalizadas, que permiten integrar contenidos de diferentes webs en un mismo sitio se centraliza la información que el usuario utiliza habitualmente. Se crea de esta manera su propio escritorio en Internet, accesible desde cualquier PC ya que se trata de una aplicación en línea, creando de esta manera una experiencia completamente nueva en lo que a navegación se refiere.

Estas tecnologías al utilizar código abierto permiten que las aplicaciones sean fácilmente escalables. La posibilidad de personalizar las interfaces por el propio usuario facilita el acceso rápido y filtrado a los recursos más utilizados sin pérdida de tiempo en búsquedas interminables. En un mundo con un abanico de información tan amplio, este hecho se puede considerar de vital importancia. 


\section{Bibliografía}

(1) Morgan Stanley - Institucional Services Estado de Internet.

<http://www.morganstanley.com/institutional/techresearch/webtwopto2006.html >

(2) 20minutos.es: "España líder en Europa del uso de Internet. País europeo con más blogs". <http://www.20minutos.es/noticia/202140/0/blogs/espana/pionera/ >

(3) Auchard, Eric. "Participation on Web 2.0 sites remains weak" [en línea]: Reuters. 17 Abril 2007. <http://www.reuters.com/article/technologyNews/idUSN1743638820070418 >

(4) Nielsen, Jacob. "Participation Inequality: Encouraging More Users to Contribute" [en línea]: Jakob Nielsen's Alertbox. 9 Octubre 2006.

<http://www.useit.com/alertbox/participation inequality.html > [Consulta: 6 mayo, 2007].

(5) google.dirson.com, noticias Google en español [en línea].

<http://google.dirson.com/post/2885-google-compra-youtube/ > [Consulta: 29 mayo, 2007].

(6) El País. "Google sigue renovando su fondo de armario". [en línea]

<http://www.elpais.com/articulo/internet/Google/sigue/renovando/fondo/armario/elpeputec/2007 0524elpepunet 3/Tes $>$ [Consulta: 29 mayo, 2007].

(7) Dave Sifry. Technorati Weblog. The State of the Live Web, April 2007. [en línea] <http://technorati.com/weblog/2007/04/328.html > [Consulta: 29 mayo, 2007].

(8) Dave Sifry. Technorati Weblog. The State of the Live Web, April 2007. [en línea] <http://technorati.com/weblog/2007/04/328.html > [Consulta: 29 mayo, 2007].

(9) Dra. Claudia Quadros. Revista Latina de Comunicación Social. "Clinton-Lewinsky: el escándalo que comenzó en la Red”. Agosto de 1999. [en línea] <http://www2.ull.es/publicaciones/latina/a1999eag/54cla.htm > [Consulta: 29 mayo, 2007]. 


\section{Anexo}

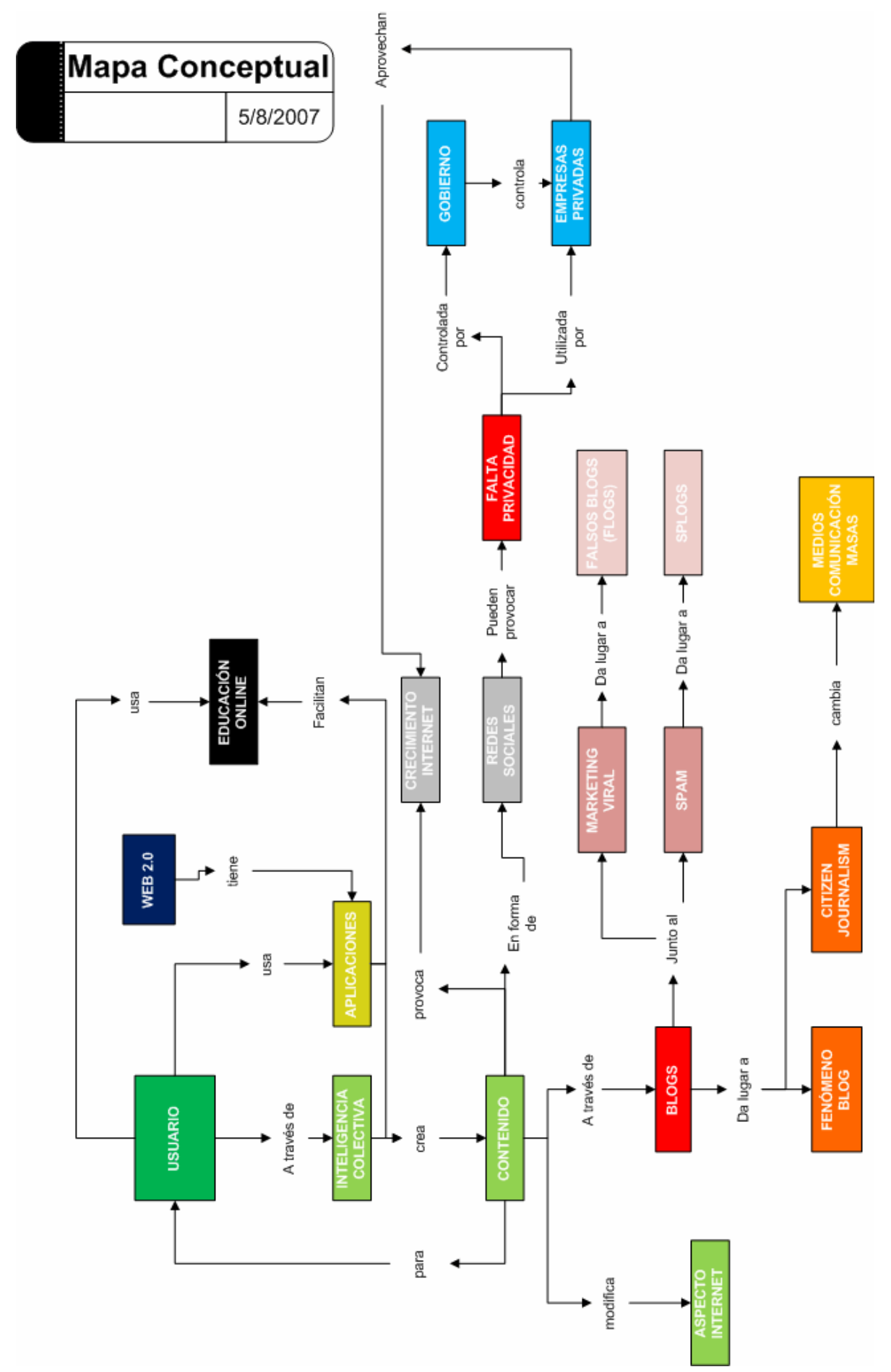

